Supplementary information to

ChAP 1.0: A stationary tropospheric sulphur

cycle for Earth system models of intermediate complexity

Alexey V. Eliseev, Rustam D. Gizatullin, and Alexandr V. Timazhev 


\section{Governing equations:}

$$
\begin{aligned}
U \cdot \frac{\partial B}{\partial x} & =E-k B \\
\frac{\partial B}{\partial t} & \equiv 0
\end{aligned}
$$

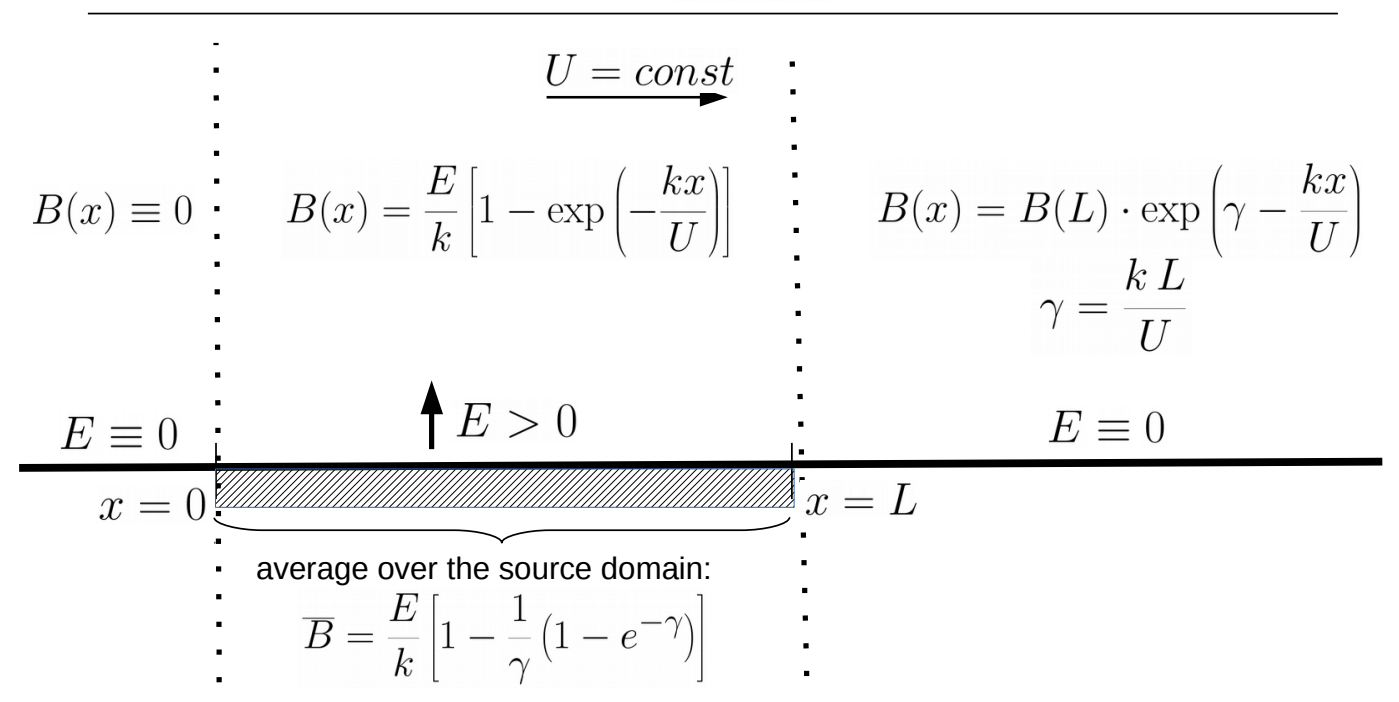

Fig. S1. Solution of the one-dimensional emission-transport problem in three characteristic domains. External emissions with the per-area rate $E$ are applied only in the domain $0 \leq x \leq L$. Notations: $B$ is burden per unit area, $k$ is loss coefficient, $U$ is horizontal wind speed, $x$ is horizontal coordinate. In contrast to Eqs. (5) and (6) of the main text, subscripts indicating chemical substances are dropped for simplicity. 
a)

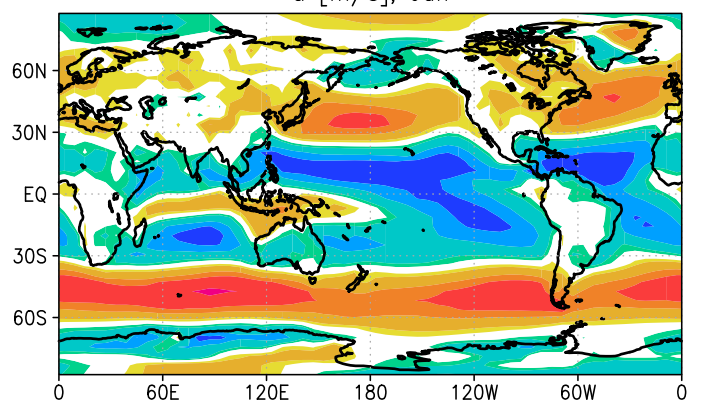

c)

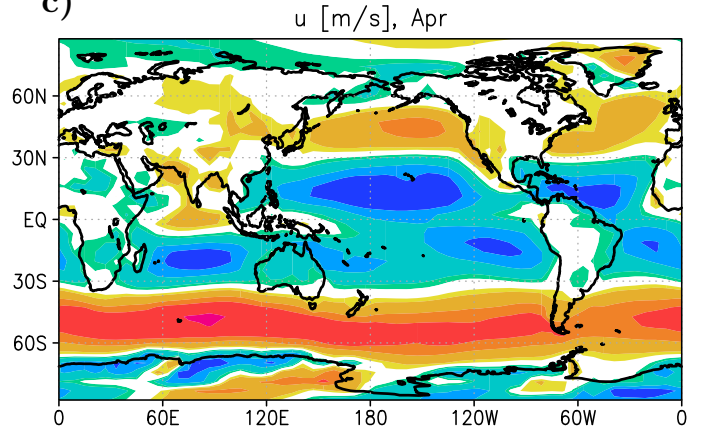

e)

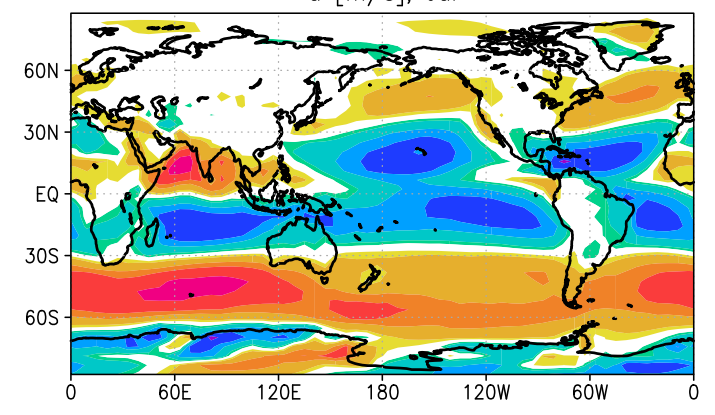

g)

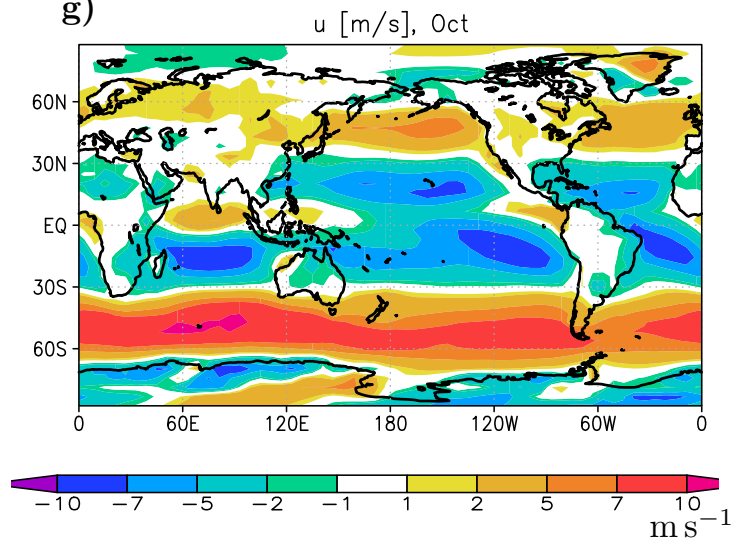

b)

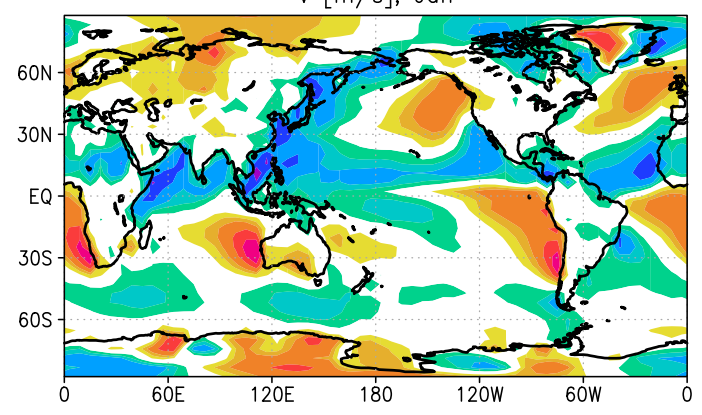

d)

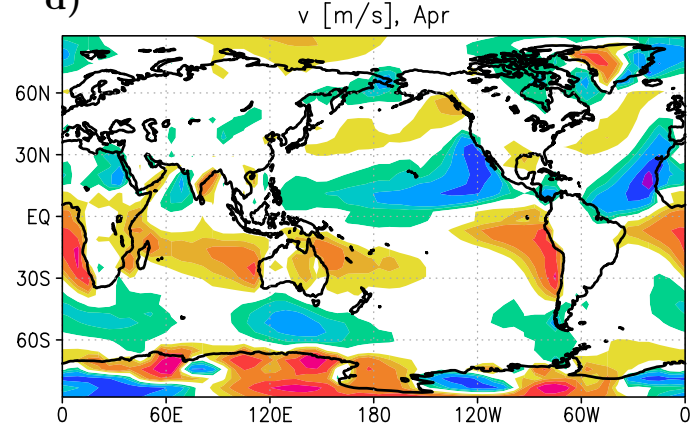

f)

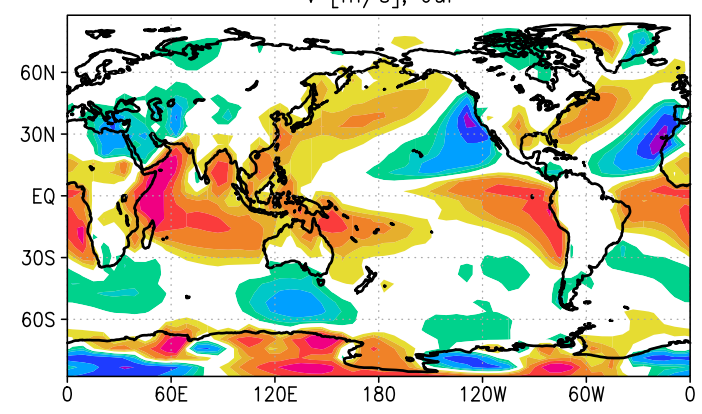

h)
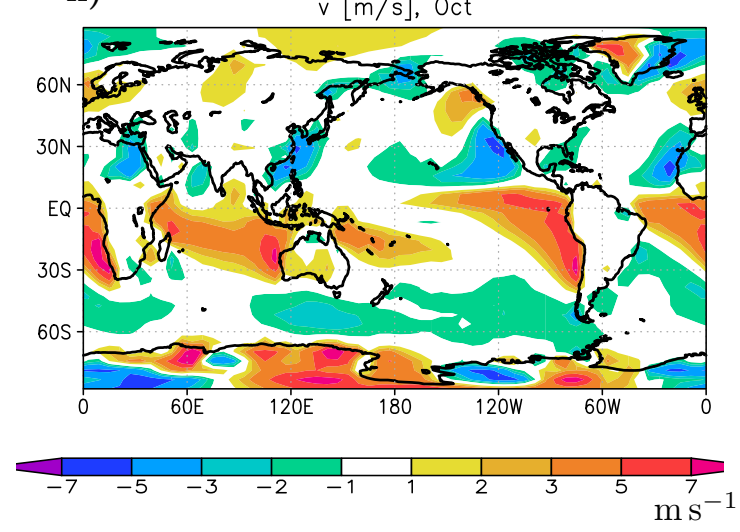

Fig. S2. ERA-Interim horizontal wind components averaged over years 19792015 at the $850 \mathrm{hPa}$ isobaric level. 
a)

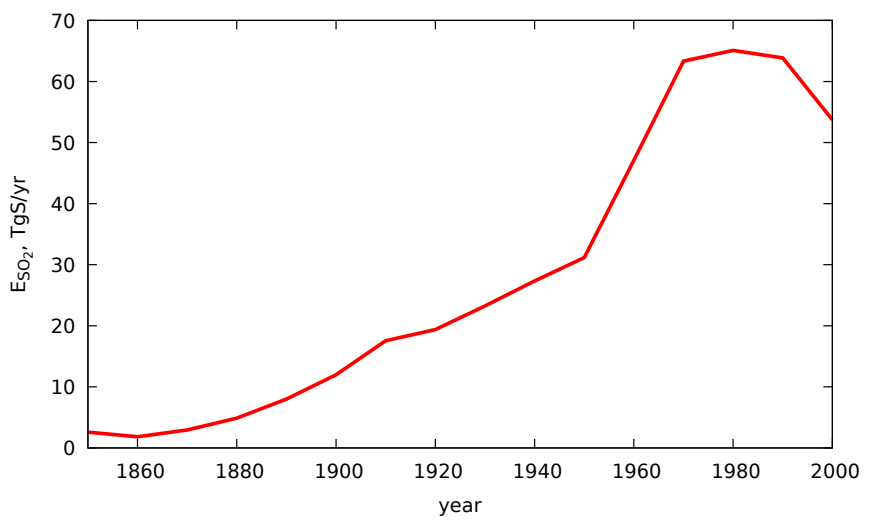

b)

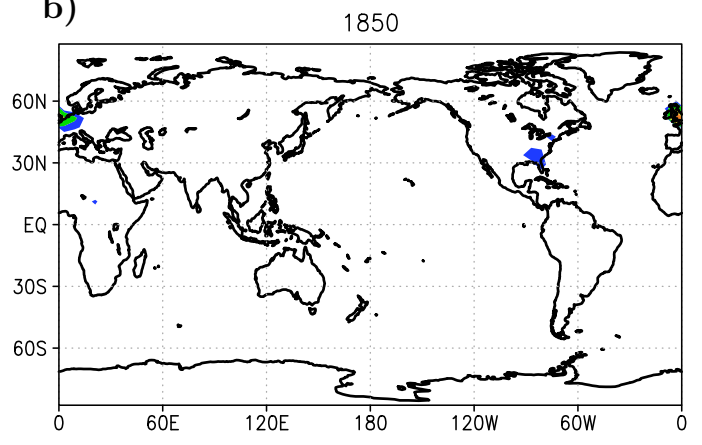

d)

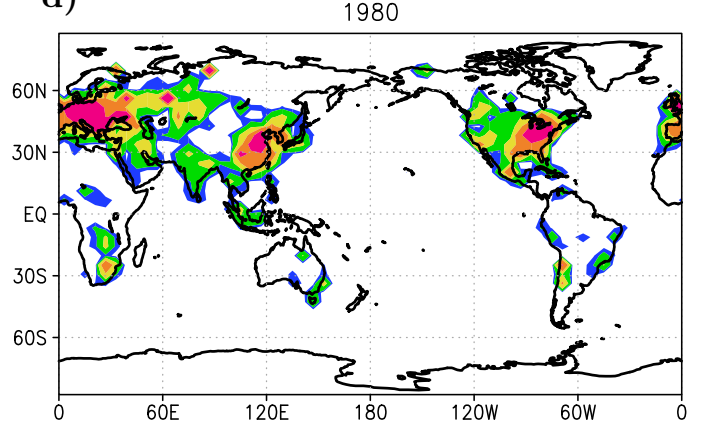

c)

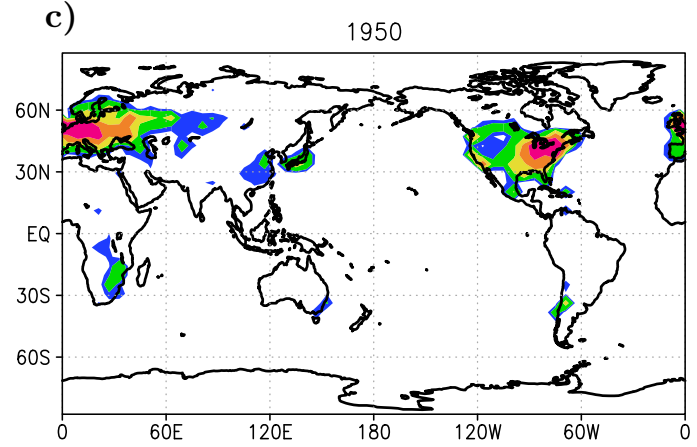

e)

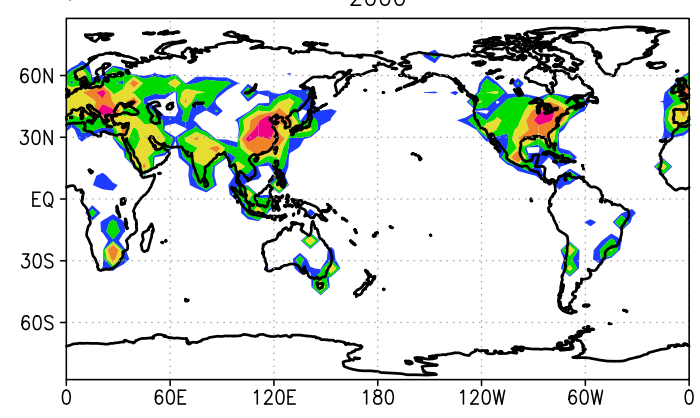

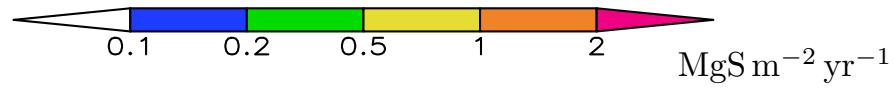

Fig. S3. Annual sulphur dioxide emissions for the CMIP5 'historical' database. Shown are the globally averaged time series (a) and the maps for the selected time slices $(b-e)$. 
a) CAMS $B_{\mathrm{SO}_{2}}$, ann 2003-2010

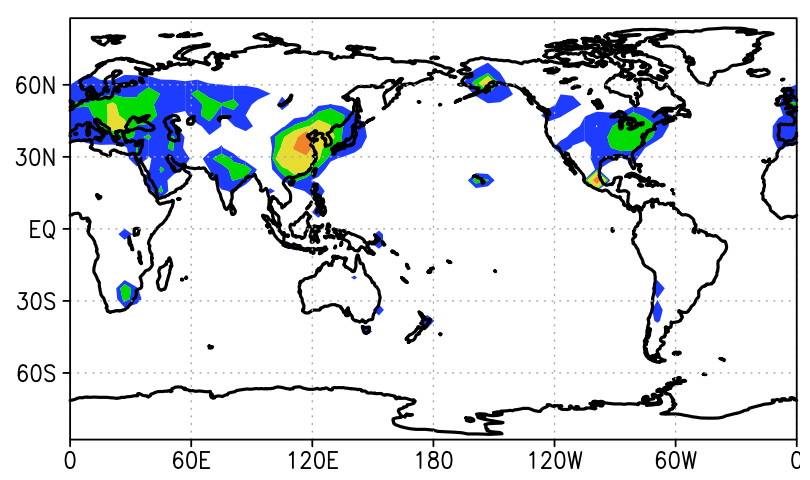

c) CAMS $B_{\mathrm{SO}_{2}}$, DJF 2003-2010

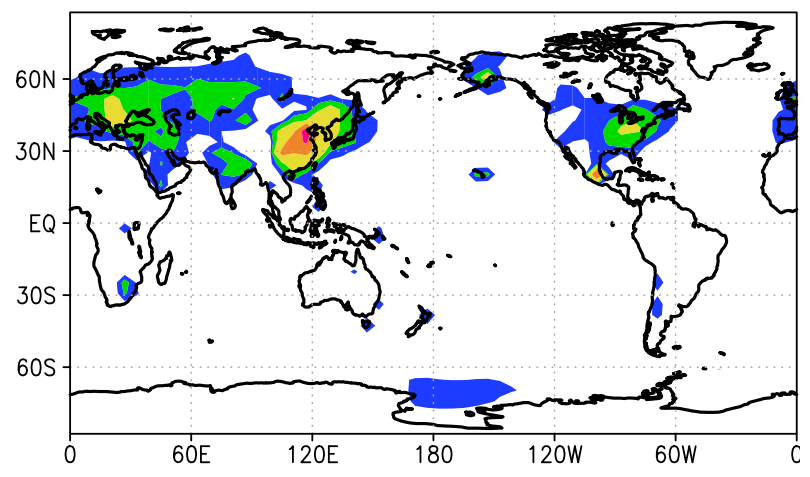

e) CAMS $B_{\mathrm{SO}_{2}}$, JJA 2003-2010

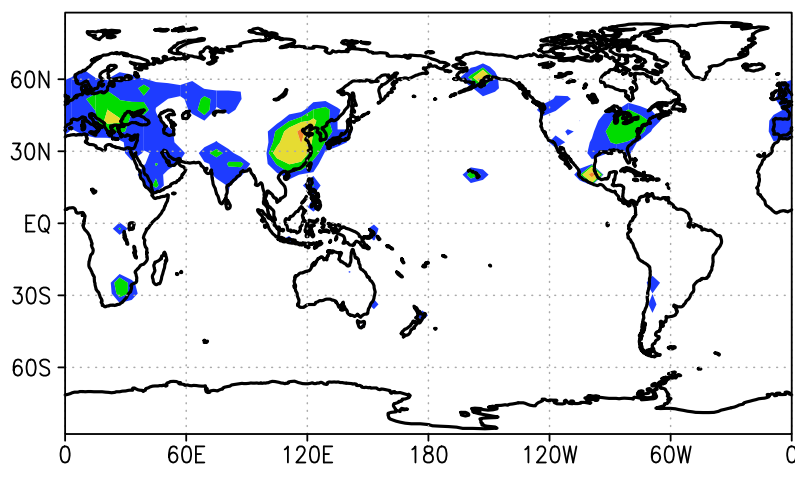

b) CAMS $B_{\mathrm{SO}_{4}}$, ann 2003-2010

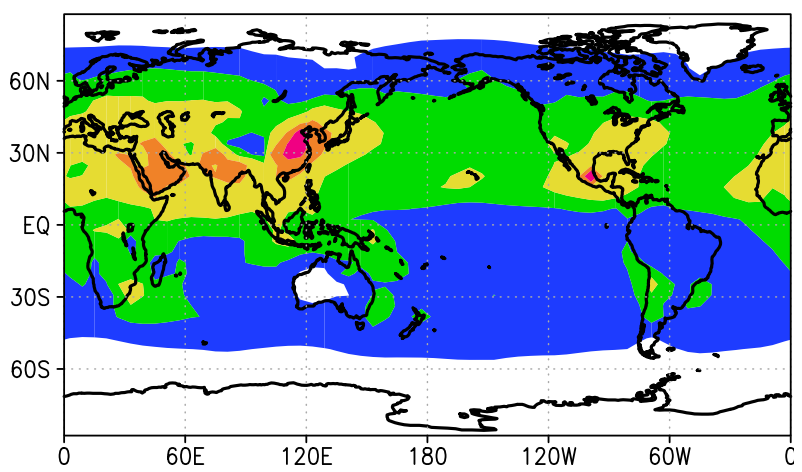

d) CAMS $B_{\mathrm{SO}_{4}}$, DJF 2003-2010

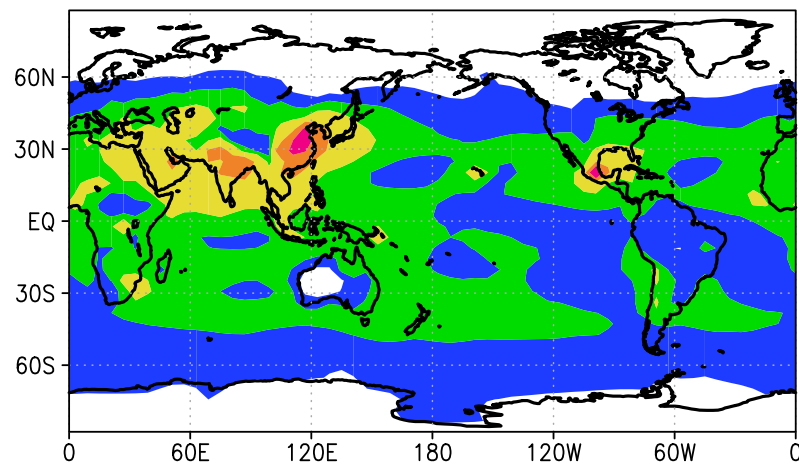

f) CAMS $B_{\mathrm{SO}_{4}}$, JJA 2003-2010

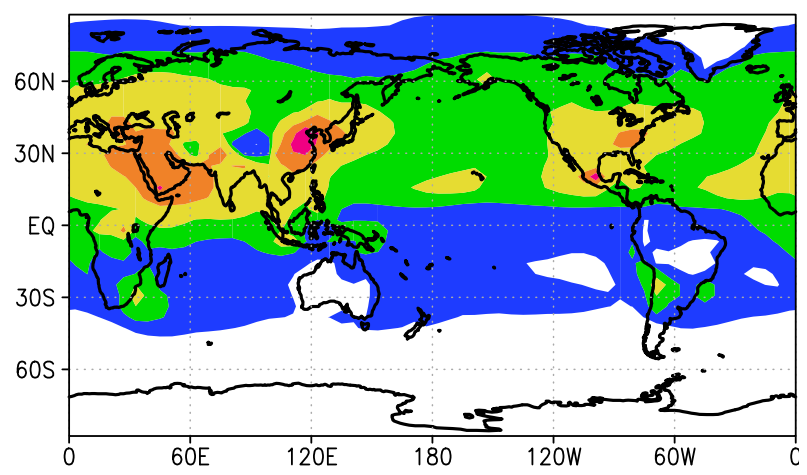

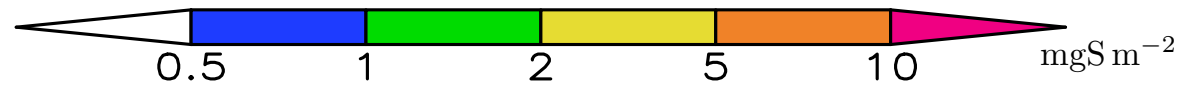

Fig. S4. Annual means $(a, b)$ and boreal winter $(c, d)$ and boreal summer $(e, f)$ means for $\mathrm{SO}_{2}(\mathrm{a}, \mathrm{c}, \mathrm{e})$ and $\mathrm{SO}_{4}(\mathrm{~b}, \mathrm{~d}, \mathrm{f})$ burdens per unit area based on the CAMS data (Inness et al., 2019) for for 2003-2010 interpolated to the $40 \times 60$ regular global latitude-longitude grid. 
a) CAMS $q_{\mathrm{SO}_{2}}$, ann 2003-2010

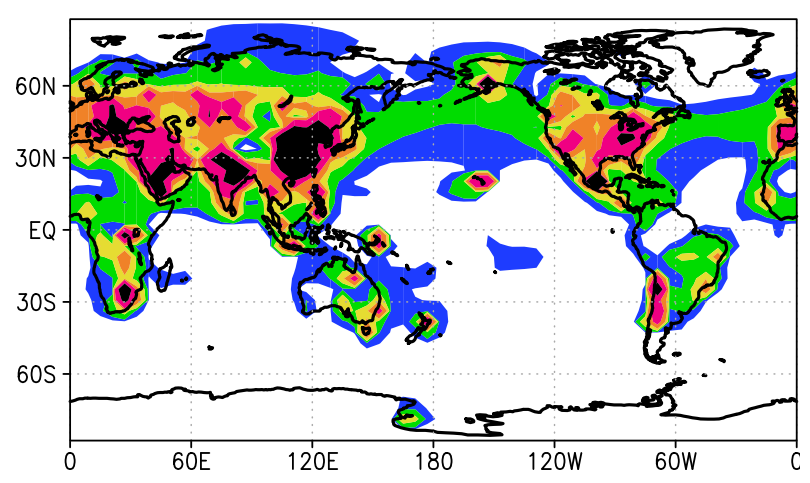

c) CAMS $q_{\mathrm{SO}_{2}}$, DJF 2003-2010

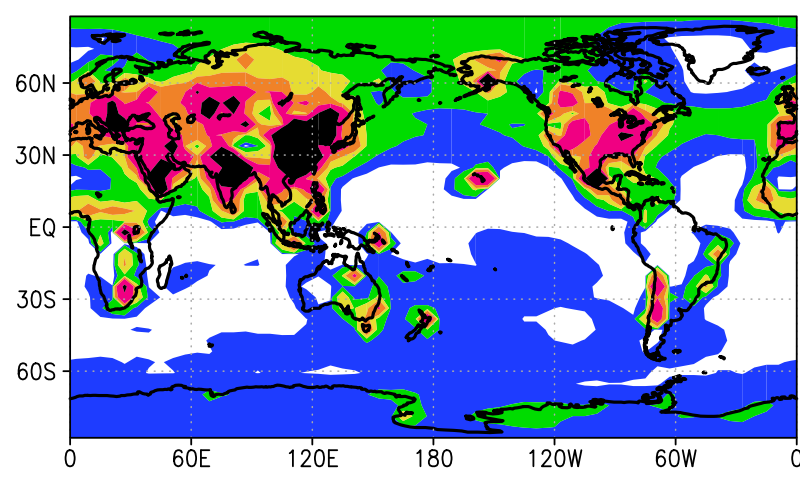

e) CAMS $q_{\mathrm{SO}_{2}}$, JJA 2003-2010

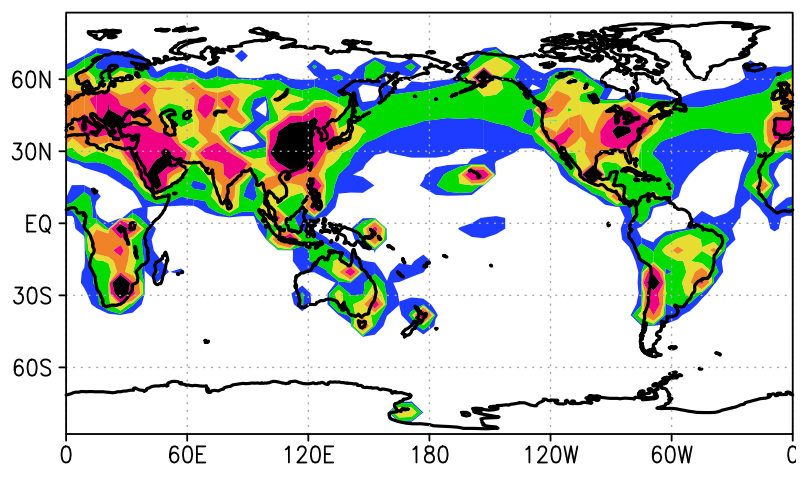

b) CAMS $q_{\mathrm{SO}_{4}}$, ann 2003-2010

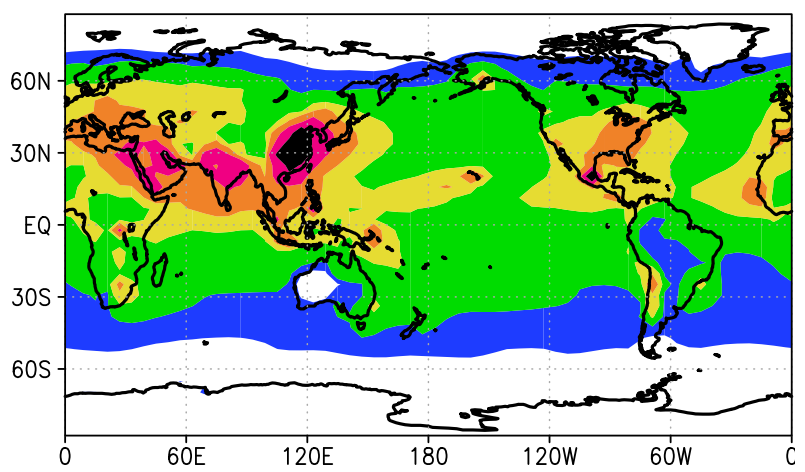

d) CAMS $q_{\mathrm{SO}_{4}}$, DJF 2003-2010

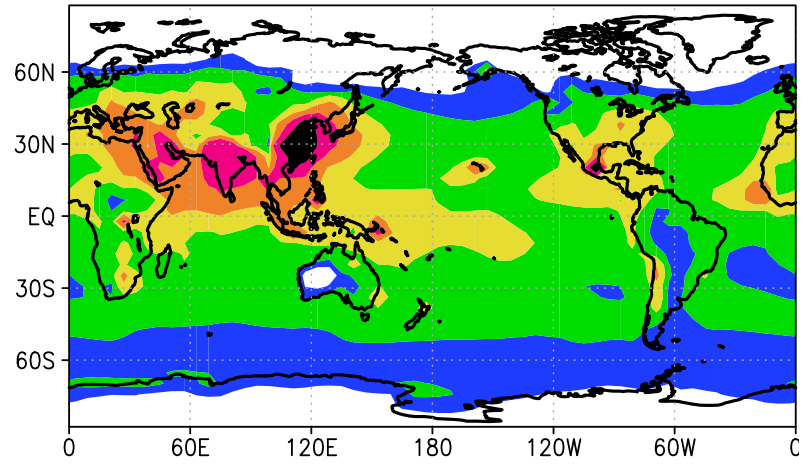

f) CAMS $q_{\mathrm{SO}_{4}}$, JJA 2003-2010

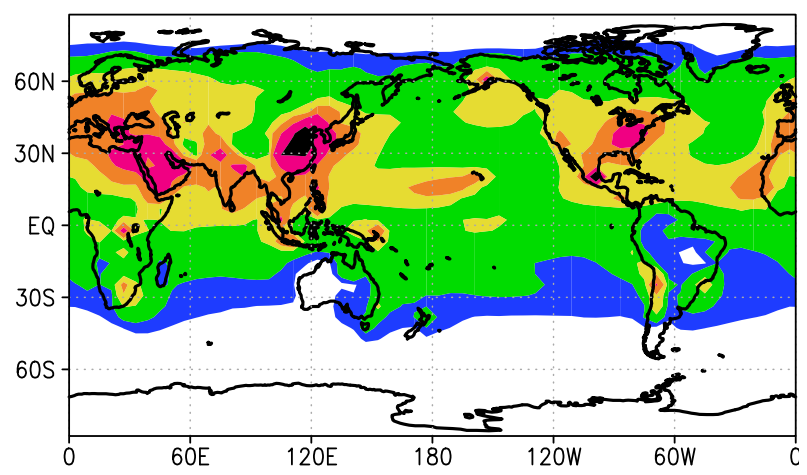

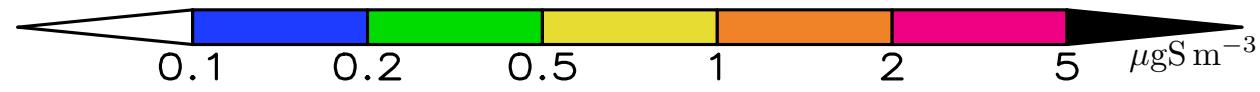

Fig. S5. Similar to Fig. S4, but for near-surface concentrations of $\mathrm{SO}_{2}$ and $\mathrm{SO}_{4}$. 
a) EMEP $q_{\mathrm{SO}_{2}}$, ann 2000-2005

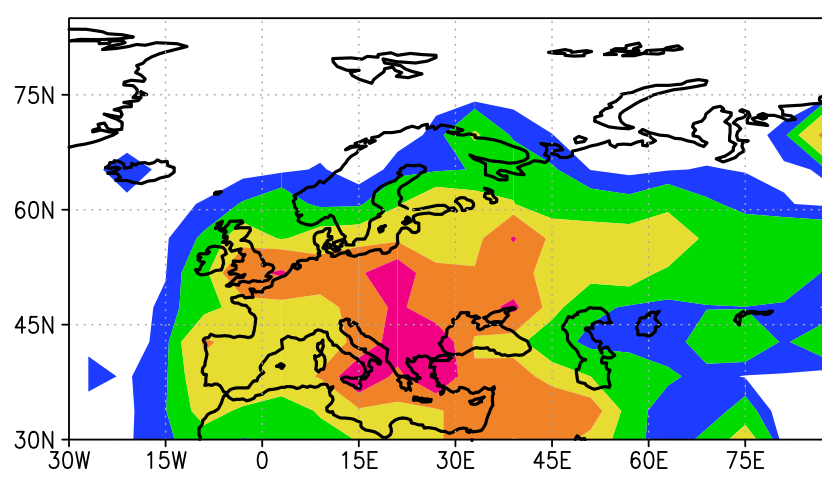

c) EMEP $q_{\mathrm{SO}_{2}}$, DJF 2000-2005

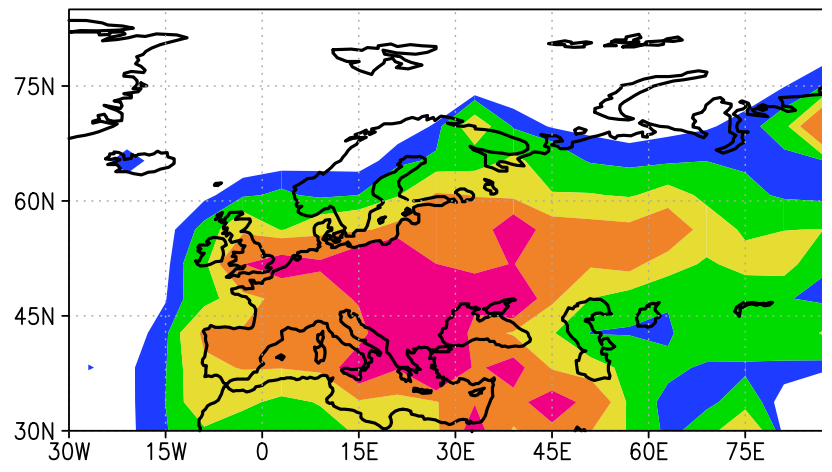

e) EMEP $q_{\mathrm{SO}_{2}}$, JJA 2000-2005

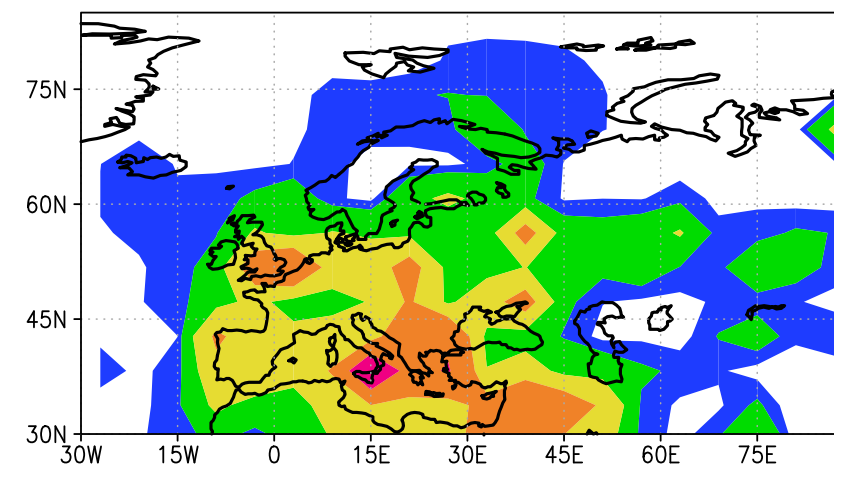

b) EMEP $q_{\mathrm{SO}_{4}}$, ann 2000-2005

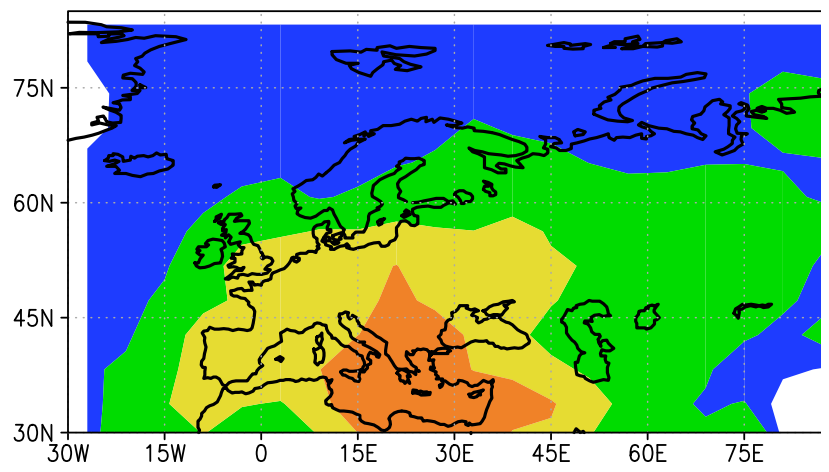

d) EMEP $q_{\mathrm{SO}_{4}}$, DJF 2000-2005

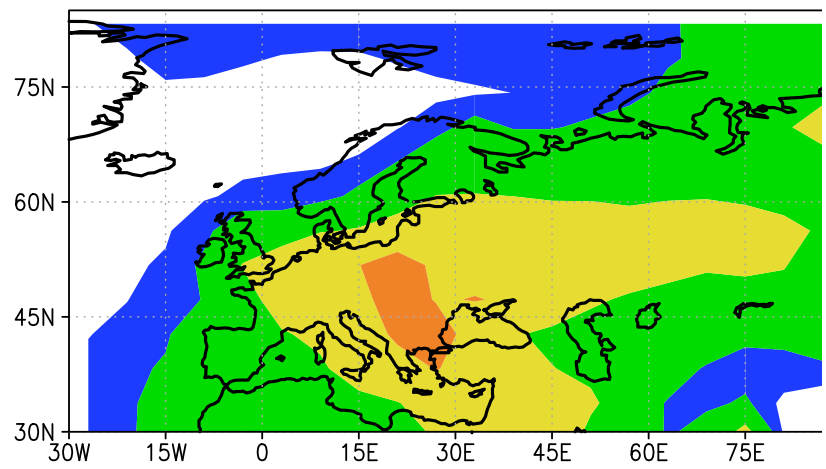

f) $\mathrm{EMEP} q_{\mathrm{SO}_{4}}$, JJA 2000-2005

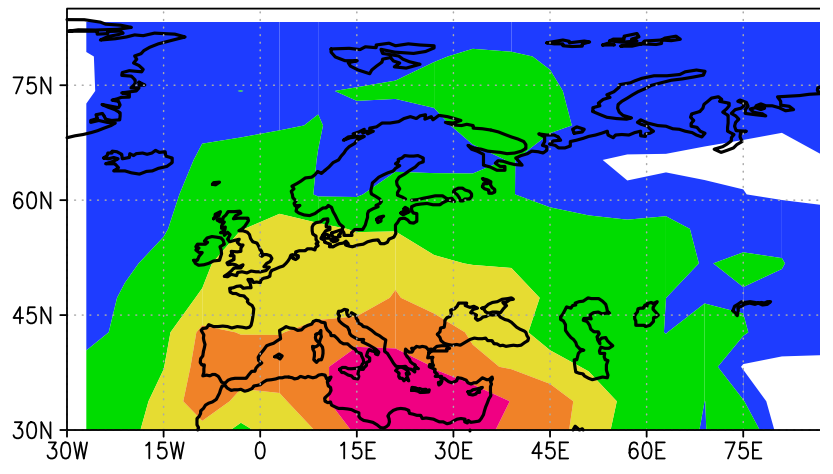

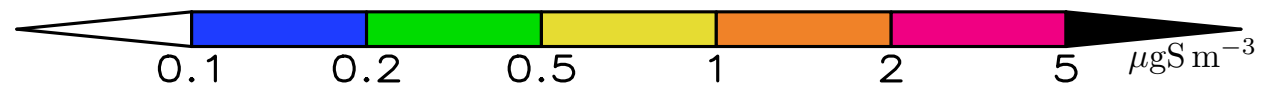

Fig. S6. Similar to Fig. S5, but based on the EMEP MSC-W data (Simpson et al., 2012) for 2000-2005 in their computational domain. 
a) model $D_{\mathrm{SO}_{\mathrm{x}}}$, ann 1980

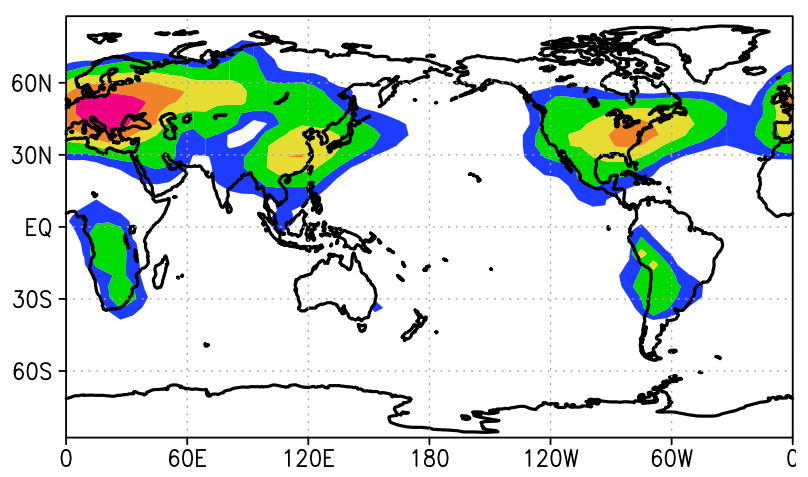

c) model $D_{\mathrm{SO}_{x}, \text { wet }}$, ann 1980

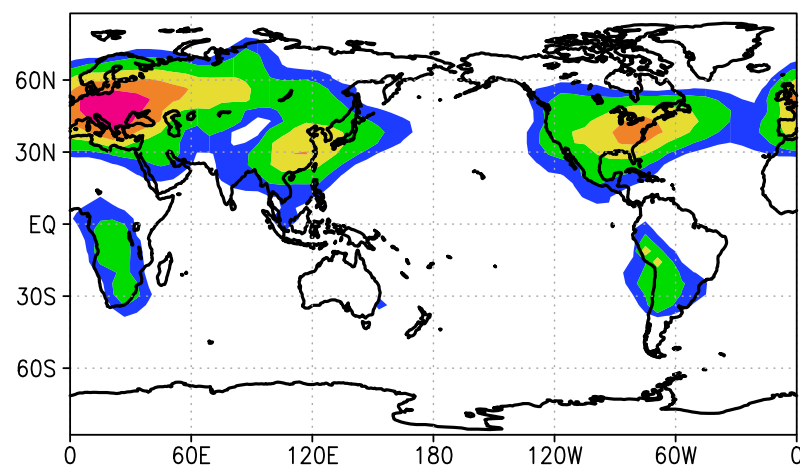

e) model $D_{\mathrm{SO}_{\mathrm{x}}, \mathrm{dry}}$, ann 1980

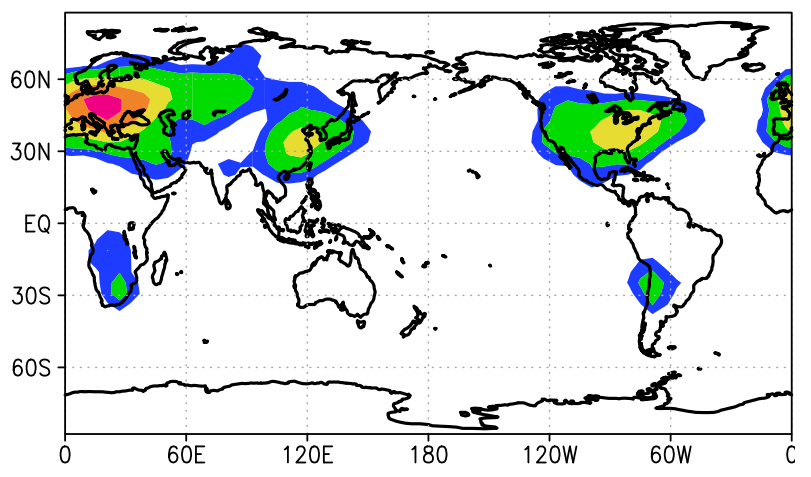

b) ACCMIP $D_{\mathrm{SO}_{x}}$, ann 1980

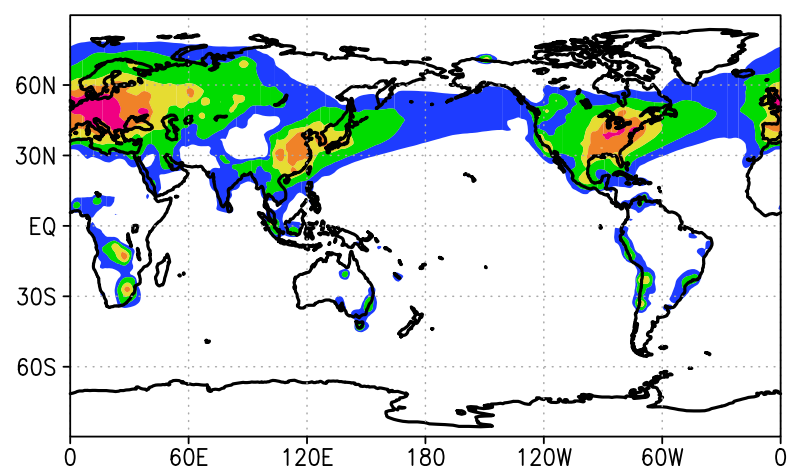

d) ACCMIP $D_{\mathrm{SO}_{x}, \text { wet }}$, ann 1980

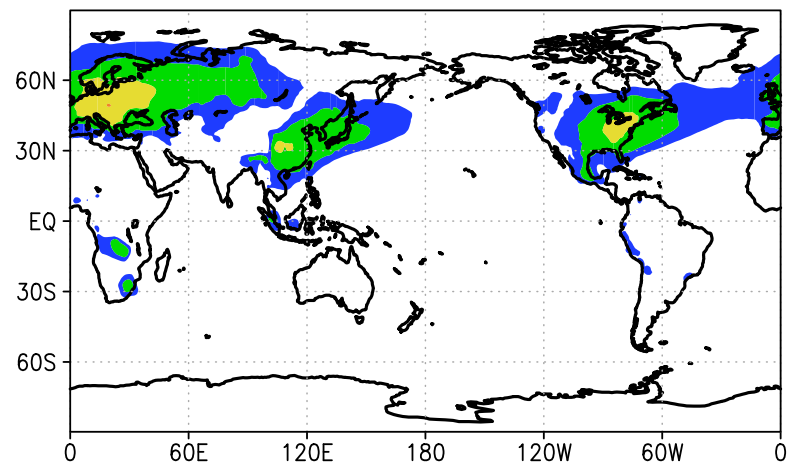

f) ACCMIP $D_{\mathrm{SO}_{x}, \text { dry }}$, ann 1980

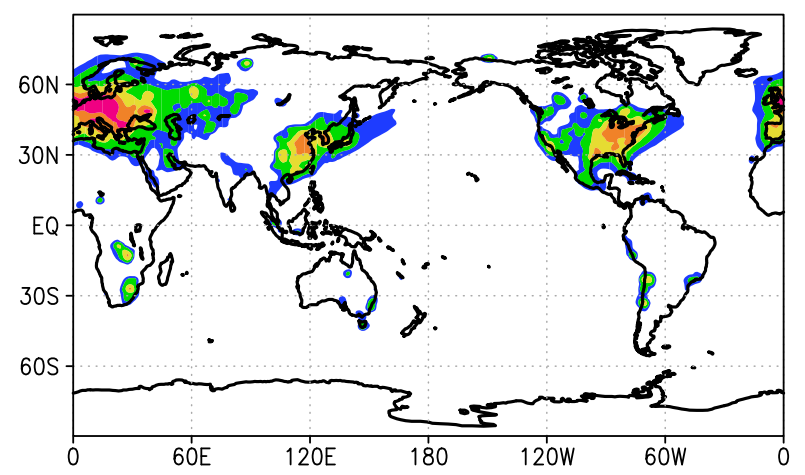

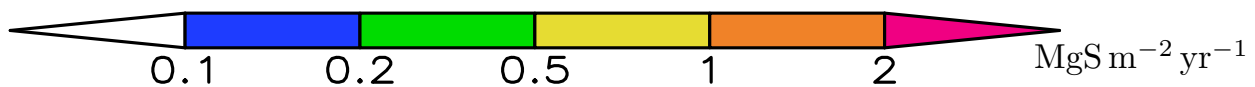

Fig. S7. Total (a, b), wet (c, d), and dry $(e, f) \mathrm{SO}_{\mathrm{x}}$ depositions per unit area in the model (a, c, e) and in the ACCMIP simulations (b, d, f) for year 1980. The ACCMIP data are from (Lamarque et al., 2013). These plots are similar to the plots in panels b-g in Fig. 9 of the main text correspondingly. 
a) EMEP $D_{\mathrm{SO}_{x} \text {,wet }}$, ann 2000-2005

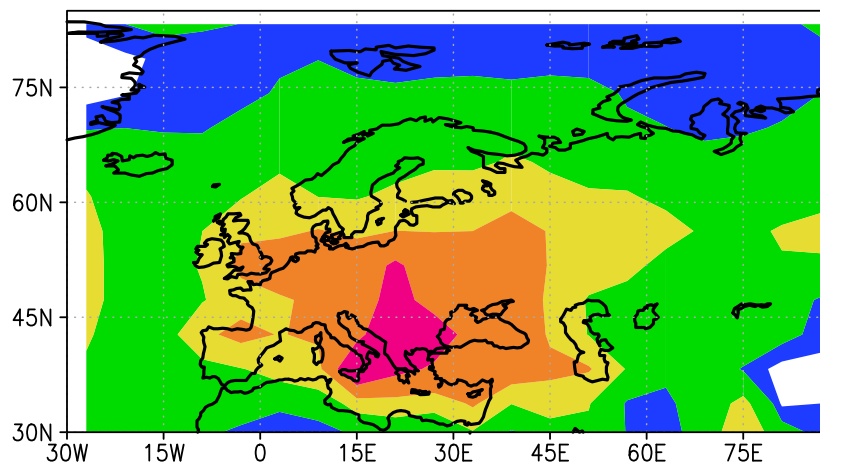

b) EMEP $D_{\mathrm{SO}_{\mathrm{x}}, \mathrm{dry}}$, ann 2000-2005
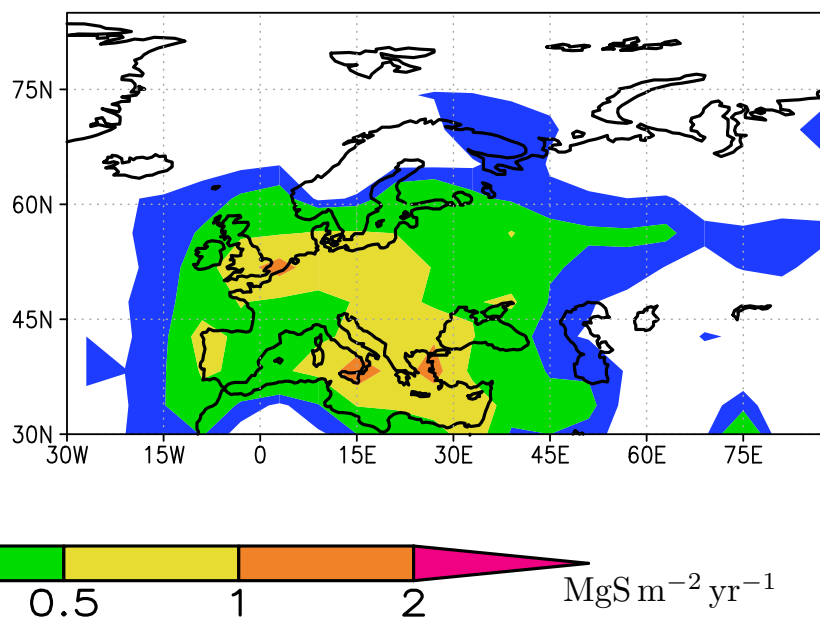

Fig. S8. Annual wet (a) and dry (b) $\mathrm{SO}_{\mathrm{x}}$ depositions based on the EMEP data for 2000-2005 interpolated to the $40 \times 60$ regular latitude-longitude grid. 


\section{References}

Inness, A., Ades, M., Agustí-Panareda, A., Barré, J., Benedictow, A., Blechschmidt, A.-M., Dominguez, J., Engelen, R., Eskes, H., Flemming, J., Huijnen, V., Jones, L., Kipling, Z., Massart, S., Parrington, M., Peuch, V.H., Razinger, M., Remy, S., Schulz, M., and Suttie, M.: The CAMS reanalysis of atmospheric composition, Atmos. Chem. Phys., 19, 3515-3556, https://doi.org/10.5194/acp-19-3515-2019, 2019.

Lamarque, J.-F., Dentener, F., McConnell, J., Ro, C.-U., Shaw, M., Vet, R., Bergmann, D., Cameron-Smith, P., Dalsoren, S., Doherty, R., Faluvegi, G., Ghan, S., Josse, B., Lee, Y., MacKenzie, I., Plummer, D., Shindell, D., Skeie, R., Stevenson, D., Strode, S., Zeng, G., Curran, M., Dahl-Jensen, D., Das, S., Fritzsche, D., and Nolan, M.: Multi-model mean nitrogen and sulfur deposition from the Atmospheric Chemistry and Climate Model Intercomparison Project (ACCMIP): evaluation of historical and projected future changes, Atmos. Chem. Phys., 13, 7997-8018, https://doi.org/10.5194/acp-13-7997-2013, 2013.

Simpson, D., Benedictow, A., Berge, H., Bergström, R., Emberson, L., Fagerli, H., Flechard, C., Hayman, G., Gauss, M., Jonson, J., Jenkin, M., Nyíri, A., Richter, C., Semeena, V., Tsyro, S., Tuovinen, J.-P., Valdebenito, Á., and Wind, P.: The EMEP MSC-W chemical transport model - technical description, Atmos. Chem. Phys., 12, 7825-7865, https://doi.org/10.5194/acp-127825-2012, 2012. 